\title{
The impact of land surface temperature on soil moisture anomaly detection from passive microwave observations
}

\author{
R. M. Parinussa ${ }^{1,2}$, T. R. H. Holmes ${ }^{1}$, M. T. Yilmaz $^{1}$, and W. T. Crow ${ }^{1}$ \\ ${ }^{1}$ USDA ARS Hydrology and Remote Sensing Laboratory, Beltsville, MD, USA \\ ${ }^{2}$ Department of Hydrology and Geo-environmental Sciences, Faculty of Earth and Life Sciences, \\ VU University Amsterdam, Amsterdam, The Netherlands
}

Received: 5 July 2011 - Published in Hydrol. Earth Syst. Sci. Discuss.: 11 July 2011

Revised: 3 October 2011 - Accepted: 10 October 2011 - Published: 17 October 2011

\begin{abstract}
For several years passive microwave observations have been used to retrieve soil moisture from the Earth's surface. Low frequency observations have the most sensitivity to soil moisture, therefore the current Soil Moisture and Ocean Salinity (SMOS) and future Soil Moisture Active and Passive (SMAP) satellite missions observe the Earth's surface in the L-band frequency. In the past, several satellite sensors such as the Advanced Microwave Scanning Radiometer-EOS (AMSR-E) and WindSat have been used to retrieve surface soil moisture using multi-channel observations obtained at higher microwave frequencies. While AMSR-E and WindSat lack an L-band channel, they are able to leverage multi-channel microwave observations to estimate additional land surface parameters. In particular, the availability of Ka-band observations allows AMSR-E and WindSat to obtain coincident surface temperature estimates required for the retrieval of surface soil moisture. In contrast, SMOS and SMAP carry only a single frequency radiometer and therefore lack an instrument suited to estimate the physical temperature of the Earth. Instead, soil moisture algorithms from these new generation satellites rely on ancillary sources of surface temperature (e.g. re-analysis or near real time data from weather prediction centres). A consequence of relying on such ancillary data is the need for temporal and spatial interpolation, which may introduce uncertainties. Here, two newly-developed, large-scale soil moisture evaluation techniques, the triple collocation (TC) approach and the $R_{\text {value }}$ data assimilation approach, are applied to quantify the
\end{abstract}

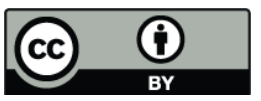

Correspondence to: R. M. Parinussa (robert.parinussa@falw.vu.nl) global-scale impact of replacing Ka-band based surface temperature retrievals with Modern Era Retrospective-analysis for Research and Applications (MERRA) surface temperature output on the accuracy of WindSat and AMSR-E based surface soil moisture retrievals. Results demonstrate that under sparsely vegetated conditions, the use of MERRA land surface temperature instead of Ka-band radiometric land surface temperature leads to a relative decrease in skill (on average $9.7 \%$ ) of soil moisture anomaly estimates. However the situation is reversed for highly vegetated conditions where soil moisture anomaly estimates show a relative increase in skill (on average $13.7 \%$ ) when using MERRA land surface temperature. In addition, a pre-processing technique to shift phase of the modelled surface temperature is shown to generally enhance the value of MERRA surface temperature estimates for soil moisture retrieval. Finally, a very high correlation $\left(R^{2}=0.95\right)$ and consistency between the two evaluation techniques lends further credibility to the obtained results.

\section{Introduction}

Surface soil moisture plays an important role in many waterand energy related studies and is an important parameter in several applications, such as numerical weather predictions (e.g. Loew et al., 2009), global change monitoring, the prediction of surface runoff (Brocca et al., 2010) and the modelling of evaporation (Miralles et al., 2011). Soil moisture is the key to our understanding of the interaction between the land and the atmosphere as it determines the distribution of energy at the subsurface and consequently impacts associated water fluxes. Most recently (November 2009) the European

Published by Copernicus Publications on behalf of the European Geosciences Union. 
Space Agency (ESA) launched the Soil Moisture and Ocean Salinity (SMOS) satellite, which is designed to retrieve surface soil moisture at coarse spatial resolution $(40 \times 40 \mathrm{~km})$ (Kerr et al., 2010). The upcoming National and Aeronautics and Space Administration (NASA) Soil Moisture Active and Passive (SMAP) satellite is designed for the same goal, and currently scheduled for launch in November 2014 (Entekhabi et al., 2010b). Because of the combination of passive and active microwave observation SMAP is expected to retrieve surface soil moisture at a higher spatial resolution $(10 \times 10 \mathrm{~km})$. Both missions will operate in the L-band frequency $(\sim 1.4 \mathrm{GHz})$ which should, in theory, possess the highest sensitivity to surface soil moisture (e.g. Jackson and Schmugge, 1989; Schmugge, 1983).

A variety of satellites have been observing the Earth surface with multi-frequency (C-, X-, K- and Ka-band, respectively $\sim 6.8, \sim 10.7, \sim 19$ and $\sim 37 \mathrm{GHz}$ ) passive microwave radiometers from the late 1970's onwards and are used for the retrieval of surface soil moisture (e.g. Owe et al., 2008). The Advanced Microwave Scanning Radiometer for the Earth Observing System (EOS) program (AMSR-E) on board NASA's Aqua satellite was the first widely used sensor for soil moisture retrievals. The WindSat polarimetric radiometer on board of the Coriolis satellite is based on AMSR-E with small changes in specifications (Gaiser et al., 2004). Recently, Parinussa et al. (2011) showed that soil moisture retrievals from both satellites are of similar quality when compared to in situ data after the implementation of an inter-calibration procedure and consistent use of a retrieval algorithm. One of the major differences between the two satellites are the local equator overpass times, which are 06:00 a.m./p.m. for the Coriolis satellite (identical to SMOS and SMAP) and 01:30 a.m./p.m. for the Aqua satellite. Another important difference is the reduced temporal frequency of WindSat at a fixed point on the ground due to its smaller swath width $(1025 \mathrm{~km})$ relative to AMSR-E $(1445 \mathrm{~km})$.

Several algorithms to estimate surface soil moisture from AMSR-E and WindSat observations exist (e.g. Jackson et al., 2004; Owe et al., 2008; Li et al., 2010). Results of these soil moisture algorithms have been validated on varying scales using several types of observations and methods (e.g. Wagner et al., 2007; Draper et al., 2009; Jackson et al., 2010; Crow et al., 2010; Li et al., 2010). All algorithms developed for the retrieval of soil moisture from these two radiometers use a combination of observations in several frequencies and/or several polarizations. Land surface temperature (LST) is considered to be a critical input parameter for soil moisture retrievals and several algorithms rely on Ka-band observations to retrieve this parameter. In particular, Holmes et al. (2009) developed a retrieval method which is based on a simple linear relation between vertical polarized Ka-band observations and LST. Because the newly designed missions (SMOS and SMAP) are single frequency (L-band) they lack an instrument suited to estimating the physical temperature of the Earth. Instead, algorithms to re- trieve soil moisture from the new generation satellites rely on ancillary temperature data, such as re-analysis or near real time data from weather prediction centres, to acquire temperature estimates and retrieve soil moisture. In contrast with the multi-frequency approaches, which provide coincident observations, this approach requires temporal and spatial interpolation of the ancillary data which may introduce uncertainties.

One of the algorithms using exclusively satellite observations is the Land Parameter Retrieval Model (LPRM; Owe et al., 2008). This model uses a simple radiative transfer equation to retrieve soil moisture and vegetation optical depth from horizontal and vertical polarized brightness temperatures by partitioning the observed signal into its respective soil and vegetation emission components (e.g. de Jeu and Owe, 2003; Meesters et al., 2005). Because soil moisture and vegetation optical depth are retrieved simultaneously, the temperature estimate affects both the soil and the vegetation component which could lead to a potential feedback in the LPRM that is not present in other soil moisture algorithms. As a result of this potential feedback, the LPRM may be one of the more sensitive algorithms with respect to errors in LST. LPRM global soil moisture retrievals from the AMSR-E and WindSat sensor have been extensively validated against in situ observations (e.g. de Jeu et al., 2008; Draper et al., 2009; Parinussa et al., 2011), models (e.g. Loew et al., 2009; Crow et al., 2010; Bisselink et al., 2011) and other satellite soil moisture products (e.g. Wagner et al., 2007; Scipal et al., 2008; Dorigo et al., 2010). These studies show that LPRM soil moisture captures a high degree of the temporal variability (correlation coefficient) in spatially-averaged soil moisture estimated obtained from high-density ground gauge networks (Wagner et al., 2007; Draper et al., 2009; Jackson et al., 2010). This finding was confirmed by Crow et al. (2010) using a completely different approach (the $R_{\text {value }}$ method) and using soil moisture anomalies rather than absolute values. The skill to capture a high degree of temporal variability of soil moisture was the main driver to select LPRM soil moisture retrievals for this study. For the majority of the applications and/or data assimilation techniques that use remotely sensed soil moisture data the temporal correlation coefficient is arguably the most important indicator of utility. Especially for data assimilation it is a prerequisite to minimize systematic differences (Reichle and Koster, 2004), often by removing the climatology and scaling the anomalies to match the models climatology (e.g. by cumulative distribution function (CDF)-matching).

In this paper the impact of LST on the capability to detect soil moisture anomalies relative to a climatological expectation is evaluated. The analysis is executed on a quasi-global $\left(50^{\circ} \mathrm{N}-50^{\circ} \mathrm{S}\right)$ scale, based on $8 \mathrm{yr}$ of data and two different evaluation techniques. Large-scale validation/verification of surface soil moisture retrievals is generally hampered by a lack of ground-based observation networks with sufficient spatial density to be accurately up-scaled to the 
resolution of satellite-based soil moisture retrievals (Scipal et al., 2008). Recently, ground-based observations have been made more readily available (http://www.ipf.tuwien.ac. at/insitu/ and http://www.wcc.nrcs.usda.gov/scan/), enhancing the evaluation of remotely sensed soil moisture using ground-based observations over a wide range of land cover types (e.g. Brocca et al., 2011; Parinussa et al., 2011). Nonetheless, global scale applications increasingly require global scale estimates of the skill of soil moisture data that isolated monitoring networks cannot provide. For this reason, two new evaluation techniques have been proposed which circumvent the need for extensive ground-based soil moisture observations and can be applied globally.

The first technique is the $R_{\text {value }}$ method which was introduced by Crow and Zhan (2007) and was recently adapted (Crow et al., 2010) to run on an anomaly basis and using a Rauch-Tung-Striebel smoother instead of a Kalman filter. This method is based on calculating the Pearson correlation coefficient $\left(R_{\text {value }}\right)$ between rainfall errors and Kalman filter analysis increments realized during the assimilation of remotely sensed soil moisture products into an antecedent precipitation index (API). In this paper we used the recently adapted version presented in Crow et al. (2010).

The second evaluation technique is based on the so-called Triple Collocation (TC) analysis which was first applied to soil moisture observations by Scipal et al. (2008). TC is a powerful statistical tool for estimating root mean square error (RMSE) in a time series of geophysical data by simultaneously solving for systematic differences in the climatology of a set of three linearly related data sources with independent error structures. Miralles et al. (2010) validated the TC technique with in situ soil moisture data from four heavily instrumented watersheds located in the United States. This technique was also used by Dorigo et al. (2010) to rank the quality of different soil moisture products to inform a merger of active and passive microwave based soil moisture products.

Our analysis is based on the application of both the TC and $R_{\text {value }}$ verification techniques to globally evaluate the impact of changing between Ka-band and MERRA-based LST products on the anomaly detection accuracy of subsequent LPRM-based AMSR-E and WindSat soil moisture retrievals. The use of both TC and $R_{\text {value }}$ methods allows for the crossverification of key results and the first attempt at comparing results from both metrics on a global scale. It also allows for an initial global evaluation of various pre-processing strategies for re-analysis based LST products. Recently, Holmes et al. (2011) argued that time-lagged pre-processing of the MERRA LST observations can improve their accuracy as a representation of the temperature for surface soil moisture retrieval algorithms. Their approach is based on synchronizing temperature observations via the introduction of a phase shift to temperature observations at different depths. This phase shift may vary with land cover and surface state, since these properties determine the propagation of heat through deeper soil layers. In evaluating several scenarios, based on this phase shift, we hope to better understand errors in SMOS and SMAP soil moisture retrievals associated with the use of temperature estimates from ancillary data. Also, potential time-lagged pre-processing of the MERRA LST predictions following Holmes et al. (2011) will be evaluated to determine the potential use of phase shifting approaches to enhance the utility of LST products obtained from an atmospheric re-analysis system.

This paper is organized as follows. Section 2 describes the main characteristics of the data sets used in this study, and the temporal and spatial selection procedures. This is followed by a description of the two evaluation techniques and the different LST scenarios in Sect. 3. In Sect. 4 the results are presented and discussed, starting with the cross verification of the two evaluation metrics followed by the results of the evaluated LST scenarios. Finally, Sect. 5 describes the conclusions and outline of future research.

\section{Data}

\subsection{Passive microwave observations}

The Advanced Microwave Scanning Radiometer for Earth Observing System (AMSR-E) is a radiometer on board NASA's Aqua satellite which was launched on 4 May 2002. The satellite orbits the Earth at an altitude of $705 \mathrm{~km}$ and scans with an incidence angle of $55^{\circ}$. Observations are made in vertical and horizontal polarization at six frequencies, three of which are relevant for this study $-6.9 \mathrm{GHz}$ (C-band), $10.7 \mathrm{GHz}$ (X-band) and $37 \mathrm{GHz}$ (Ka-band). The spatial resolution of the $\mathrm{C}-, \mathrm{X}$ - and Ka-band observations are $73 \times 43 \mathrm{~km}, 51 \times 30 \mathrm{~km}$ and $14 \times 8 \mathrm{~km}$, respectively. For more detailed information on the Aqua AMSR-E sensor readers are directed to NSIDC (2006). The design of the WindSat radiometer, on board the Coriolis satellite which was launched on 6 January 2003, is based on AMSR-E and has only small changes in specifications (e.g. frequency, bandwidth, incidence angle and calibration procedure; Table 2). Recently, Parinussa et al. (2011) showed that soil moisture retrievals from both satellites are of similar quality when compared to in situ data after the implementation of an inter-calibration procedure and consistent use of the LPRM retrieval algorithm. The WindSat satellite orbits the Earth at an altitude of $840 \mathrm{~km}$ and scans with an incidence angle of $53.5^{\circ}, 49.9^{\circ}$ and $53.0^{\circ}$ for C-, X- and Ka-band, respectively. For more detailed information on the Coriolis WindSat sensor readers are directed to Gaiser et al. (2004). The main characteristics of the two radiometers and satellites which are relevant for this study are summarized in Table 2.

An important difference between AMSR-E and WindSat is the reduced temporal frequency of WindSat observations as a result of the reduced swath width. Another difference is the local equator overpass times, which are 06:00 a.m./p.m. for the Coriolis satellite (identical to SMOS and SMAP) and 
01:30 a.m./p.m. for the Aqua satellite. These differences motivate the use of both WindSat and AMSR-E retrievals in this analysis. In particular, the 06:00 a.m./p.m. overpass time of WindSat matches SMOS and SMAP. This is critical since at the 06:00 a.m./p.m. overpass times of the Coriolis satellite, the soil temperature profile is considered to be more vertically homogeneous than at the 01:30 a.m./p.m. overpass times of the Aqua satellite. However, since the reduced temporal frequency of WindSat observations may introduce higher levels of sampling error in evaluation results, we have also included the AMSR-E results in the analysis. Finally, the physical conditions of the observed surface are significantly different for the day- (ascending) and nighttime (descending) overpass, and are therefore separated in the analysis.

Radio frequency interference (RFI) disturbs the natural microwave emission in the C-band frequency over significantly large areas over the United States, India and Japan. The RFI algorithm developed by Li et al. (2004) was used to detect these areas for both satellites. If RFI was detected on a specific location we switched back to observations in the somewhat higher X-band frequency (Fig. 1) for the entire analysis period.

\subsection{MERRA data}

The Modern Era Retrospective-analysis for Research and Applications (MERRA) is a multi-decadal $(30+\mathrm{yr})$ continuous re-analysis data record developed to support NASA's Earth science objectives (Rienecker et al., 2011). MERRA provides the science and application communities with global analysis with an emphasis on improved estimates of the global hydrological cycle. Three dimensional diagnostics are produced at a 6-hourly interval, while two dimensional diagnostics (including LST) are produced at an hourly interval. This high temporal interval was the main driver of using MERRA LST in this analysis. MERRA data products are coarse scale, having a spatial resolution of $1 / 2^{\circ}$ latitude by $2 / 3^{\circ}$ longitude. In this study, MERRA LST data are downscaled to $1 / 2^{\circ}$ latitude by $1 / 2^{\circ}$ longitude using nearest neighbour re-sampling and observation times were matched with the average $1 / 2^{\circ}$ observation times of the satellites.

The MERRA surface temperature product was analysed by Holmes et al. (2011), with the focus on the implementation for soil moisture retrievals. In order to account for possible differences between the depth of MERRA's surface layer and the shallow temperature sensing depth for C- and Xband, several scenarios of the MERRA re-analysis products will be evaluated that reflect slightly different soil depths. MERRA data is publically available through the Goddard Earth Sciences Data and Information Services Centre http: //disc.sci.gsfc.nasa.gov/mdisc/data-holdings for more information on the MERRA data, readers are directed to http: //gmao.gsfc.nasa.gov/merra.

\subsection{Precipitation data}

Two separate satellite based rainfall data sets produced by Tropical Rainfall Measuring Mission (TRMM) Multisatellite Precipitation Analysis (TMPA; Huffman et al., $2007)$ are also utilized: $P^{\text {sat }}$ and $P^{\text {gauge }}$. $P^{\text {sat }}$ is based on the real-time TRMM 3B42RT product calculated by combining passive microwave with microwave calibrated infrared satellite data derived from different sensors (Huffman et al., 2007). $P^{\text {gauge }}$ is based on the same satellite input data (TRMM 3B42) but includes a retrospective correction based on monthly rain gauge data. Hufmann et al. (2007) demonstrated the substantially higher quality of $P^{\text {gauge }}$ after the retrospective correction of $P^{\text {sat }}$. Both precipitation products are produced quasi-globally $\left(50^{\circ} \mathrm{N}-50^{\circ} \mathrm{S}\right)$ at a 3-hourly interval having a spatial resolution of $1 / 4^{\circ}$. In this study, precipitation data was upscaled to $1 / 2^{\circ}$ latitude by $1 / 2^{\circ}$ longitude using spatial averaging and daily representations were generated by accumulating each precipitation product over a 24 -h period.

\subsection{Scatterometer data}

The Advanced Scatterometer (ASCAT) on board ESA's MetOp satellite is an active (radar) instrument operating in the C-band frequency $(5.255 \mathrm{GHz})$ making observations since October 2006. Backscatter measurements at six different azimuth angles are converted to surface soil moisture (SSM) estimates by applying the TU Wien soil moisture change detection algorithm (Naeimi et al., 2009). The surface soil moisture value is a relative measure of soil moisture $(\sim 1-2 \mathrm{~cm})$ ranging between wilting point and saturation. A recent validation study (Brocca et al., 2011) showed an overall high performance of the ASCAT SSM estimates for a large number of in situ ground station distributed throughout Europe. Albergel et al. (2010) found high correlations between the ASCAT SSM estimates and the surface soil moisture from the operational hydro-meteorological model of Météo-France for a region in south-western France. By the time of the analysis, the product was available from January 2007 till September 2010 and is produced in time series with a spatial resolution of $25 \mathrm{~km}$. In this study, the ascending and descending swaths are combined, which leads to a nearly daily revisit frequency at the equator. Surface soil moisture data was upscaled to $1 / 2^{\circ}$ latitude by $1 / 2^{\circ}$ longitude using spatial averaging. For more detailed information on the TU Wien soil moisture change detection algorithm readers are directed to Wagner et al. (1999) and Naeimi et al. (2009). For more detailed information on ASCAT on board the MetOp satellite readers are directed to FigaSaldana et al. (2002).

\subsection{Data selection}

Due to differences in availability and characteristics (temporal and spatial resolution) of each dataset, some compromises 


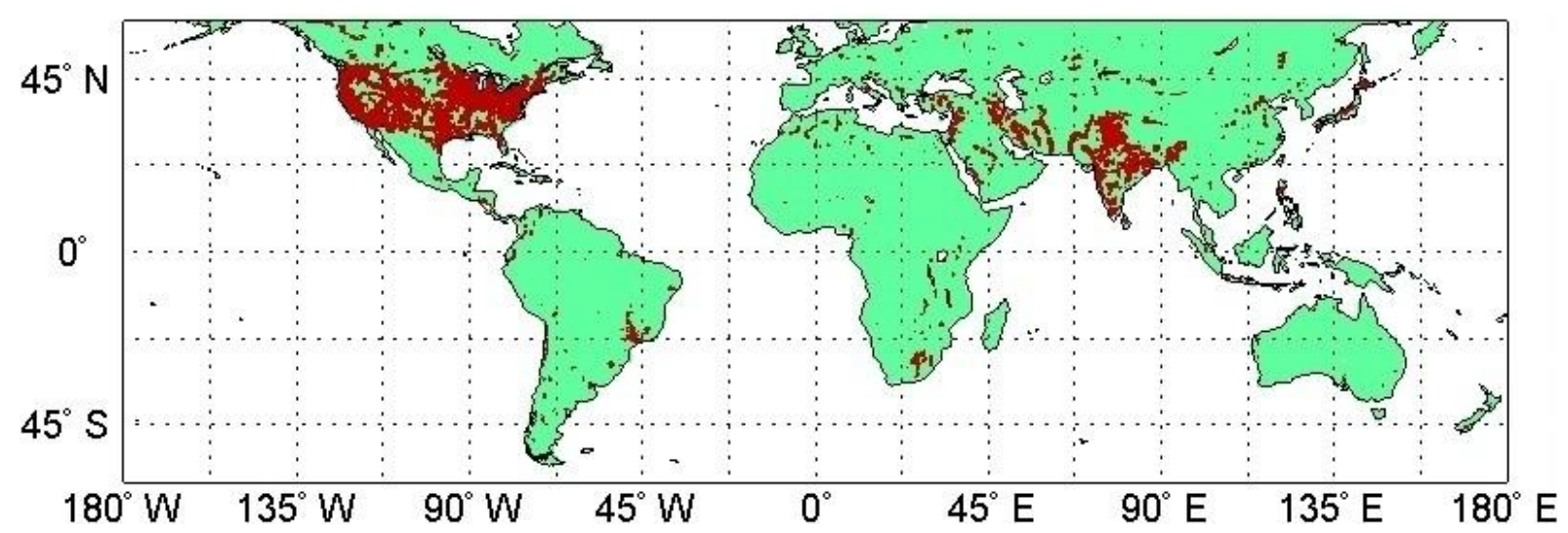

Fig. 1. The green areas indicate the areas where C-band observations are used. The red areas indicate where C-band observations are contaminated by RFI and X-band observations are used.

had to be made. By definition, the triple collocation (TC) method requires 3 independent data sources for the same geophysical variable (Sect. 3.1.2), which restricts the TC analysis to the time period of ASCAT availability between January 2007 and September 2010. The time period for which the data sets required for the $R_{\text {value }}$ method are available is significantly longer, from February 2003 till December 2010. This period was chosen to make the analysis periods of the two radiometers (AMSR-E and WindSat) identical.

The spatial resolution of the different data sets range from the highest resolution for the ASCAT data $(25 \mathrm{~km})$ to the lowest resolution for the MERRA re-analysis LST product $\left(1 / 2^{\circ}\right.$ latitude by $2 / 3^{\circ}$ longitude). The spatial resolution of the passive microwave observations are typically available at $1 / 4^{\circ}$ degree resolution. Also, the different data sets vary in their temporal resolution ranging from the highest resolution for the MERRA re-analysis (global hourly interval) to the lowest resolution for the (active and passive) microwave observation. To balance the differences in spatial and temporal availability of the data sets, the entire analysis was executed quasi-globally $\left(50^{\circ} \mathrm{N}-50^{\circ} \mathrm{S}\right)$ on a daily timescale for a $1 / 2^{\circ}$ degree spatial resolution. Moreover, the brightness temperatures from AMSR-E and WindSat were re-sampled to daily $1 / 2^{\circ}$ global grids and day- (ascending), and night (descending) time observations were analysed separate.

The results from the evaluation techniques were analysed over 6 different land cover classes (Table 1; Fig. 3) in order to categorize results according to vegetation density. The LPRM retrieves vegetation optical depth, simultaneously with the soil moisture retrievals. Daily LPRM vegetation optical depth retrievals from the night-time AMSRE overpasses were averaged for the period February 2003 till December 2010 (Fig. 2). Based on this map, the global area over which the analyses were executed $\left(50^{\circ} \mathrm{N}-50^{\circ} \mathrm{S}\right)$ is divided into 6 different classes (Table 1; Fig. 3). In the standard LPRM routine it is assumed that the soil moisture
Table 1. Boundaries to select different vegetation optical depth $(\tau)$ classes.

\begin{tabular}{lr}
\hline Class & Boundaries \\
\hline 1 & $\tau<0.1$ \\
2 & $0.1<=\tau<0.3$ \\
3 & $0.3<=\tau<0.5$ \\
4 & $0.5<=\tau<0.7$ \\
5 & $0.7<=\tau<0.9$ \\
6 & $\tau>=0.9$ \\
\hline
\end{tabular}

signal becomes entirely masked due to the overlying canopy when the simultaneously retrieved vegetation optical depth in the C-band frequency exceeds a value of 0.80 . Although the LPRM rejects soil moisture retrievals in these areas on a regular basis, they are considered in this analysis in order to inter-compare TC and $R_{\text {value }}$ results over the widest possible range of land surface conditions. Only frozen surfaces are completely removed from the analysis. For areas with detected Radio Frequency Interference, soil moisture retrievals are derived from X-band brightness temperature observations.

Both evaluation techniques require anomaly data which was calculated by decomposing the raw time series data into climatology and anomaly components. For a general geophysical variable $A$, this decomposition can be represented as

$\hat{A}_{i}=A_{i}-\bar{A}_{\mathrm{DOY}}$

where $\bar{A}_{\text {DOY }}$ is the climatological expectation of a geophysical variable from the entire analysis period, calculated using a 31-day moving window centred on a particular day of the year (DOY), and $\hat{A}_{i}$ are anomalies relative to these expectations experienced on a particular day $i$. Prior to the application of either the TC or $R_{\text {value }}$ metrics, all soil moisture and precipitation inputs were decomposed into anomalies 


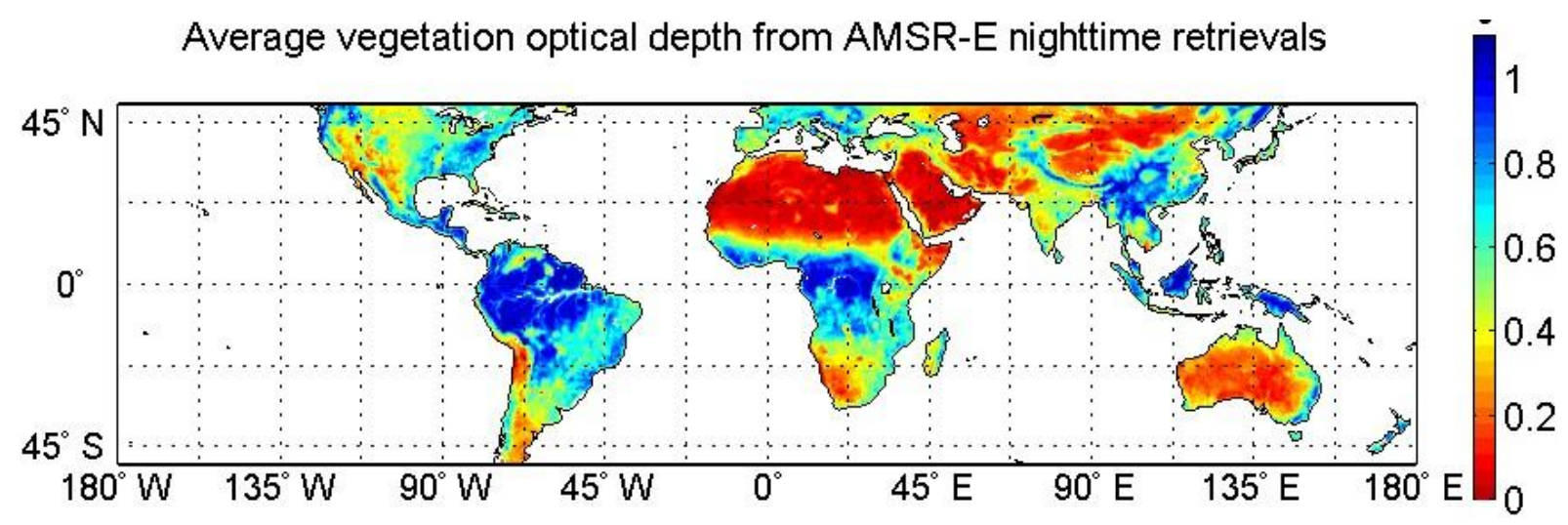

Fig. 2. Average vegetation optical depth $(\tau)$ for the AMSR-E descending overpass retrieved in the period February 2003 till December 2010. Red areas indicate low optical depth values and blue areas indicate high optical depth values.

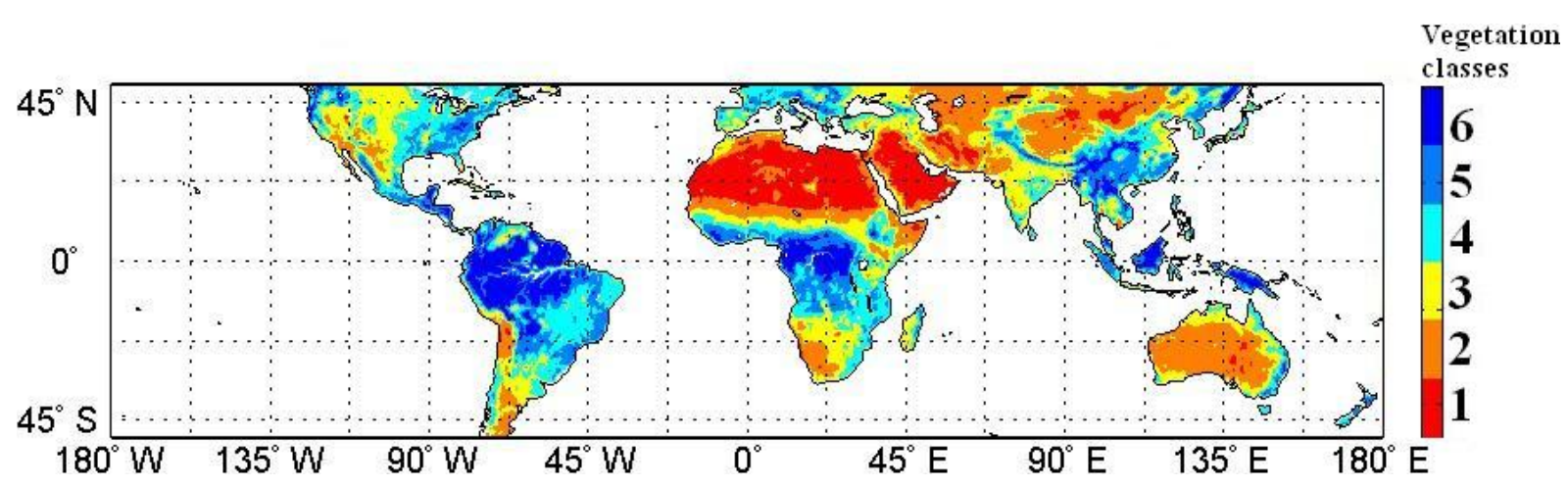

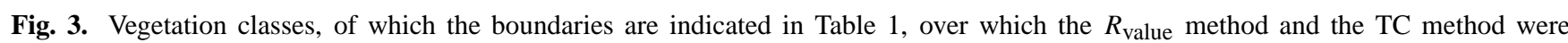
evaluated based on the simultaneously derived average vegetation optical depth $(\tau)$ of the AMSR-E descending overpass for the period February 2003 till December 2010.

Table 2. Specifications of the AMSR-E and WindSat microwave sensors used in the soil moisture retrieval algorithm.

\begin{tabular}{lll}
\hline Parameter & AMSR-E & WindSat \\
\hline Frequency $(\mathrm{GHz})$ & $6.9,10.65 \& 36.5$ & $6.8,10.7 \& 37$ \\
Bandwidth $(\mathrm{GHz})$ & $0.35,0.1 \& 1$ & $0.125,0.3 \& 2$ \\
Altitude $(\mathrm{km})$ & 705 & 840 \\
Swath width $(\mathrm{km})$ & 1445 & 1025 \\
Orbit type & Polar & Nearly polar \\
Ascending orbit & $01: 30$ p.m. & 06:00 p.m. \\
Descending orbit & $01: 30$ a.m. & 06:00 a.m. \\
Data period & May 2002 to present & January 2003 to present \\
\hline
\end{tabular}

following Eq. (1). As a result, this analysis will focus solely on evaluating the accuracy of soil moisture anomaly predictions relative to a fixed climatology. Finally, to allow for direct comparisons between the different scenarios for the LPRM, a particular $1 / 2^{\circ}$ grid for a given overpass time is only included in the analysis if it contains a viable retrieval in all evaluated scenarios.

\section{Methodology}

\subsection{Evaluation techniques}

\subsection{1 $R_{\text {value }}$ method}

The first technique is the $R_{\text {value }}$ method which was introduced by Crow and Zhan (2007) in a response to overcome practical difficulties associated with the evaluation of global products with the course spatial scale $(>25 \mathrm{~km})$ of soil moisture retrievals. The $R_{\text {value }}$ method is based on the obvious connection between rainfall and subsequent changes in soil moisture. It uses the relatively abundant rain gauge observations to indirectly evaluate the accuracy of remotely sensed surface soil moisture. The $R_{\text {value }}$ method is based on calculating the Pearson correlation coefficient $\left(R_{\text {value }}\right)$ between rainfall errors and Kalman filter analysis increments realized during the assimilation of remotely sensed soil moisture products into an antecedent precipitation index (API). Typical $R_{\text {value }}$ magnitudes range from about 0 to 0.7 , where a higher $R_{\text {value }}$ indicates high-quality soil moisture retrieval and increased efficiency in the filtering of errors in the API 
predictions resulting from random error in $P^{\text {sat }}$ used to generate API. Such errors are assumed known once the lowerquality rainfall products $\left(P^{\text {sat }}\right)$, typically obtained from a real-time precipitation dataset, is retrospectively corrected using rain gauge data, resulting in a substantially higherquality precipitation dataset $P^{\text {gauge }}$ (Huffman et al., 2007). Consequently, precipitation errors can be explicitly calculated from the difference $P^{\text {sat }}-P^{\text {gauge }}$, which can be linked to remotely sensed surface soil moisture. The approach is based on the rationale that the correlation between random rainfall errors and filter correction should increase as the accuracy of the assimilated soil moisture measurements increases.

Recently, Crow et al. (2010) adapted the $R_{\text {value }}$ approach to run on an anomaly basis (i.e. after precipitation and soil moisture products have been decomposed by Eq. (1) into anomaly components). In this case, API anomalies are defined as

$\hat{\mathrm{API}} \mathrm{I}_{i}=\gamma \cdot \hat{\mathrm{API}} \mathrm{I}_{i-1}+\hat{P}_{i}$

on a day $i$ and $\gamma$ is assumed equal to a globally constant value of 0.85. Analysis increments are then obtained by assimilating soil moisture anomalies using a Rauch-Tung-Striebel smoother and $R_{\text {value }}$ is defined as the sampled correlation coefficient between 5-day moving averages of these analysis increments and 5-day moving averages of error in $\hat{P}_{i}$.

Crow et al. (2010) verified this approach using three heavily-instrumented watersheds located in the United States. $R_{\text {value }}$ was calculated for a number of different AMSR-E soil moisture products over each site and compared to the correlation coefficient calculated between each product and extensive ground-based soil moisture observations. Results from these comparisons demonstrated that $R_{\text {value }}$ accurately captures the anomaly correlation-based skill of soil moisture retrievals without reliance on ground-based soil moisture observations. The adapted $R_{\text {value }}$ method was used in this research and for more detailed information on this method readers are directed to Crow et al. (2010). As an example of this method, the $R_{\text {value }}$ as determined for the LPRM AMSR-E (descending) soil moisture product is shown in Fig. 4.

\subsubsection{Triple collocation}

TC is a statistical tool for estimating root mean square error (RMSE) in time series based on analyzing three linearly related data sources with independent error structures. The approach has been proposed as a potential tool for the validation of remotely-sensed surface soil moisture retrievals (Scipal et al., 2008). Miralles et al. (2010) used remotely sensed-, land surface modelled- and in situ soil moisture to estimate the magnitude of point-to-footprint upscaling error for ground-based surface soil moisture observations. Dorigo et al. (2010) used remotely sensed soil moisture from 2 different (active and passive) satellite platforms and re-analysis soil moisture as the third independent data product, to rank the different satellite observed soil moisture products. Both papers used several combinations (different re-analysis or modelled data) for the third independent data product, and showed that the error estimates are only marginally influenced by the choice of this third dataset.

This paper aims to examine the relative quality of soil moisture products generated by a single retrieval algorithm. For this reason, two soil moisture data sources (API calculated from $P^{\text {gauge }}$ and ASCAT) are fixed, while the other product (soil moisture from the LPRM) is evaluated for varying scenarios. All three soil moisture data sets (i.e. $\theta_{\mathrm{ASCAT}}, \theta_{\mathrm{API}}$, and various scenarios of $\left.\theta_{\mathrm{LPRM}}\right)$ are decomposed into anomalies using Eq. (1) and we chose $\hat{\theta}_{\mathrm{ASCAT}}$ as the reference data set. Since the truth is unknown, we arbitrarily chose the ASCAT data sets as the reference which will not affect subsequent manuscript conclusions. Nevertheless, all subsequent RMSE values will be expressed in the dynamic range of this reference. Following Stofellen (1998), Scipal et al. (2008) showed that a consequence of the unknown truth is that only two of the three calibration factors can be determined leading to Eq. (3) and (4).

$\hat{\theta}_{\mathrm{API}}^{*}=\hat{\theta}_{\mathrm{API}} \cdot\left(\frac{\overline{\hat{\theta}_{\mathrm{ASCAT}} \cdot \hat{\theta}_{\mathrm{LPRM}}}}{\overline{\hat{\theta}_{\mathrm{LPRM}} \cdot \hat{\theta}_{\mathrm{API}}}}\right)$

$\hat{\theta}_{\text {LPRM }}^{*}=\hat{\theta}_{\mathrm{LPRM}} \cdot\left(\frac{\overline{\hat{\theta}_{\mathrm{ASCAT}} \cdot \hat{\theta}_{\mathrm{API}}}}{\overline{\hat{\theta}_{\mathrm{API}} \cdot \hat{\theta}_{\mathrm{LPRM}}}}\right)$

Following this decomposition Eq. (1) and scaling Eqs. (3) and (4), the RMSE of anomalies in $\hat{\theta}_{\text {LPRM }}$ can be estimated as

$\operatorname{RMSE}\left(\hat{\theta}_{\mathrm{LPRM}}\right)=\sqrt{\left\langle\left(\hat{\theta}_{\mathrm{LPRM}}^{*}-\hat{\theta}_{\mathrm{ASCAT}}\right)\left(\hat{\theta}_{\mathrm{LPRM}}^{*}-\hat{\theta}_{\mathrm{API}}^{*}\right)\right\rangle}$

where the outside angled brackets indicate temporal averaging. The accuracy of Eq. (5) relies on two key theoretical prerequisites of TC being met. First, TC requires a sufficiently large sample $(>100)$ of common observations available for temporal averaging. Second, the most important, TC requires that errors in each of three data sets are substantially uncorrelated. The latter prerequisite is difficult to fulfill (Scipal et al., 2008; Miralles et al., 2010; Dorigo et al., 2010) for soil moisture estimates obtained from complex land surface models and re-analysis systems since such approaches tend to integrate information from a wide, variety of sources. As a result, here we follow Crow and van den Berg (2010) and apply TC to soil moisture estimates obtained from a simple API modeling approach driven only by TMPA precipitation products $\left(P^{\text {gauge }}\right)$. Miralles et al. (2010) examined the impact of replacing soil moisture estimates from a highlycomplex land surface model with a simple API dataset and found that both choices lead to essentially similar TC results. Additionally, the use of a simple API model, instead 


\section{Rvalue method for AMSR-E nighttime observations}

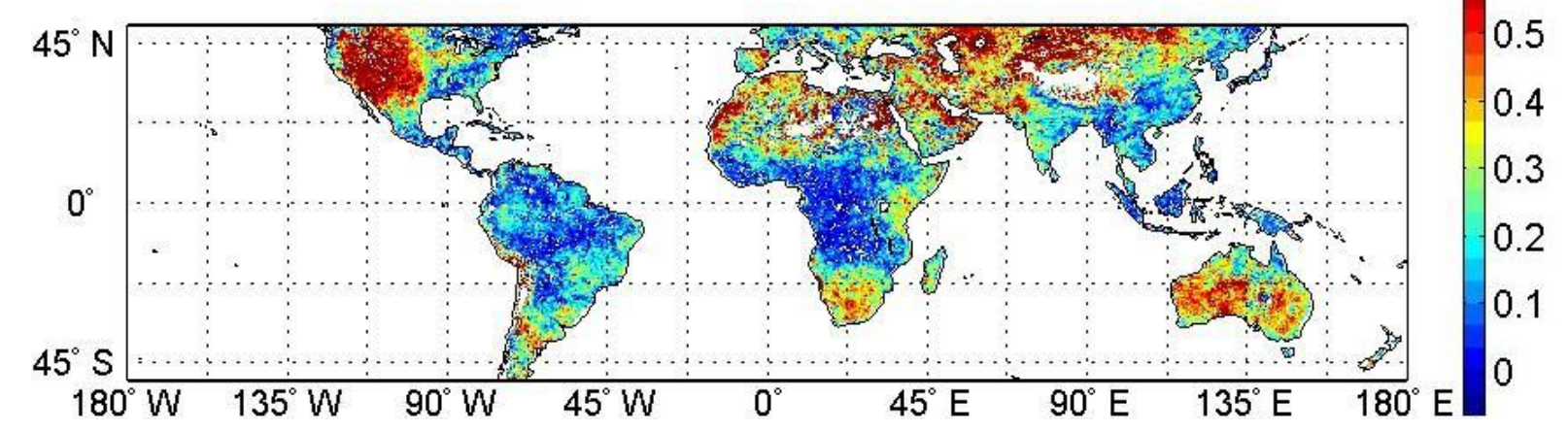

Fig. 4. Example of the $R_{\text {value }}$ method for the AMSR-E descending overpass, the analysis period was February 2003 till December 2010. Red areas indicate high $R_{\text {value }}$ outputs and blue areas indicate low $R_{\text {value }}$ outputs.

of a re-analysis soil moisture product, for the third independent product minimizes possible cross-correlation when replacing Ka-band LST by MERRA re-analysis LST data. Finally, the proposed model will only result in meaningful error estimates if the three data sets represent the same physical quantity. If one of the products does not represent the same quantity as the other two, then TC would naturally result in unrealistic error estimates for all products (more unrealistic for the non-representative data than other two), owing to the re-scaling process described above in Eqs. (3-4).

$\mathrm{TC}$ analysis is known to give highly spurious results when applied to low-accuracy data sets and some type of preprocessing is typically done to mask out such areas with poor remotely sensing results. For example Scipal et al. (2008) masked out highly-vegetated and desert areas where nonsignificant correlation coefficients were sampled between the collocated data sets. In this paper we aim to evaluate soil moisture retrievals over the widest possible range and a preselection procedure will eliminate some regions completely. Therefore, we did not apply any correlation coefficient and masked out areas with clearly non-physical TC RMSE estimates (i.e. estimated RMSE $>100$ in the ASCAT soil moisture index climatology). This relatively permissive threshold allows us to evaluate soil moisture retrievals over the widest possible range. As an example, the application of TC to the LPRM AMSR-E (descending) soil moisture retrievals product is shown in Fig. 5.

While both the $R_{\text {value }}$ and TC verification techniques have been successfully applied in previous soil moisture evaluation studies (Crow and Zhan, 2007; Crow et al., 2010; Scipal et al., 2008; Dorigo et al., 2010), their results have never been inter-compared and neither metric has achieved sufficient independent credibility to serve as true replacement for ground-based soil moisture measurements. For TC-based approaches, the primary concern is the potential for unreliable results for the case of cross-correlated errors (Scipal et al., 2008; Crow and van den Berg, 2010). For the $R_{\text {value }}$ tech- nique the analogous concern is ambiguity introduced by the uncertain choice of $\gamma$ in Eq. (2) and the potential confounding impact of auto-correlated soil moisture retrieval error (Crow and Zhan, 2007). Here we present both $R_{\text {value }}$ and TC results in an attempt to enhance the credibility of our global evaluation results by seeking results supported independently by both metrics.

The analysis period of the TC method is limited due to the availability of the ASCAT SSM dataset (2007-2010) and differs from the period used for the $R_{\text {value }}$ method (2003-2010). For both methods the climatology was calculated based on their analysis periods. A consequence of these different analysis periods is that the calculated anomalies for the longer period of the $R_{\text {value }}$ method are more statistically robust. On the other hand, the outcomes from the $R_{\text {value }}$ method depend on the amount of precipitation events during the analysis period, both differences may result in spatial inconsistencies of evaluation results. It is likely that the number of precipitation events made available for the $R_{\text {value }}$ method is the dominant factor in arid areas, since evaluation results from the $R_{\text {value }}$ verification technique appear unreliable and highly spatially heterogeneous in desert areas (Fig. 4).

\subsection{Land surface temperature scenarios}

The analysis in this paper will focus on the application of the

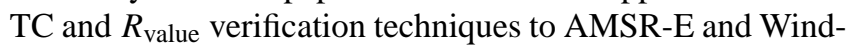
Sat surface soil moisture retrievals generated using a variety of scenarios for parameterizing LST. The first step of these scenarios will be based on the synthetic degradation of LST retrievals from Ka-band measurements (Sect. 3.2.1). This degradation will be used to assess the sensitivity of LPRM surface soil moisture retrievals to LST error, and evaluating the ability of both TC and $R_{\text {value }}$ to detect the degrading impact of this error on surface soil moisture retrievals. The second set of scenarios will be based on temperature estimates acquired from MERRA. In order to examine issues related 


\section{TC method for AMSR-E nighttime observations}

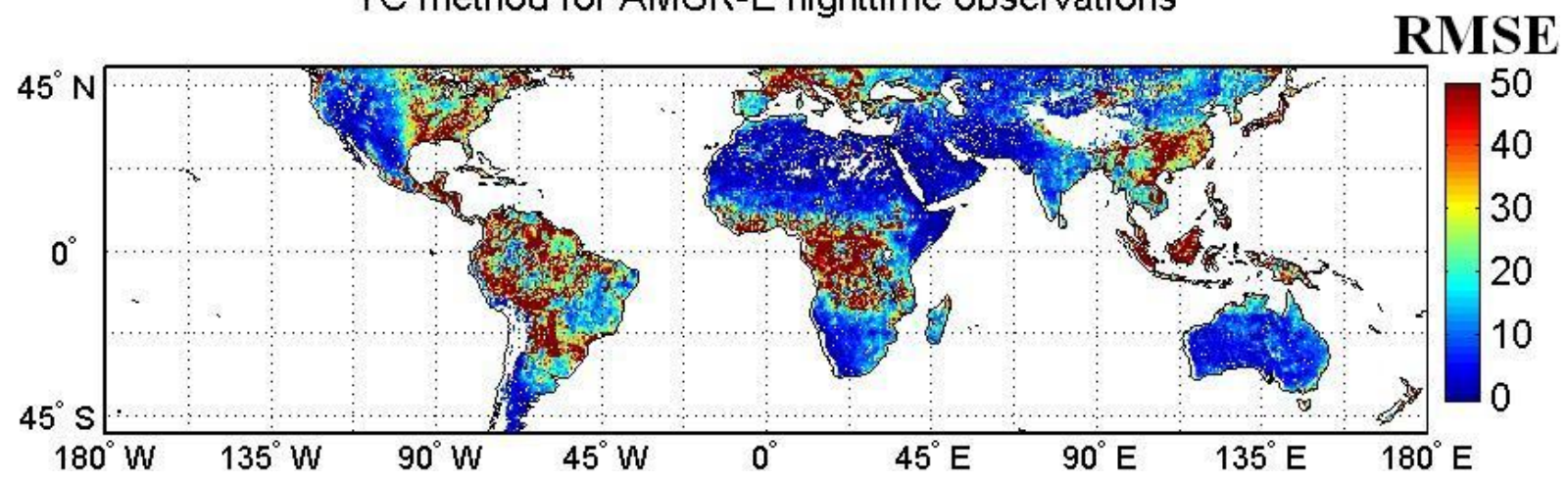

Fig. 5. Example of the TC method for the AMSR-E descending overpass, the analysis period was January 2007 till September 2010 . Blue areas indicate low TC outputs and red areas indicate high TC outputs.

Table 3. Evaluated land surface temperature scenarios.

\begin{tabular}{ll}
\hline $\begin{array}{l}\text { Ka-band LST } \\
\text { (Level of perturbation } \\
\text { in degrees Kelvin (K)) }\end{array}$ & $\begin{array}{l}\text { MERRA LST } \\
\text { (Phase shift in hours) }\end{array}$ \\
\hline $0.5 \mathrm{~K}$ & $0 \mathrm{~h}$ (original MERRA LST) \\
$1.0 \mathrm{~K}$ & $1 / 2 \mathrm{~h}$ \\
$2.0 \mathrm{~K}$ & $1 \mathrm{~h}$ \\
$4.0 \mathrm{~K}$ & \\
\hline
\end{tabular}

to the vertical depth of the soil layer that is represented by the MERRA temperature observations, several scenarios will be constructed utilizing various phase and amplitude preprocessing modifications to the MERRA surface temperature dataset (Holmes et al., 2011). Table 3 provides an overview of all LST scenarios as described in Sects. 3.2.1 and 3.2.2 which are used to detect the impact of LST on surface soil moisture retrievals.

\subsubsection{Ka-band scenarios}

LST is considered to be a critical input parameter to retrieve soil moisture and several algorithms use a method developed by Holmes et al. (2009) to retrieve this parameter. This method is based on a simple linear relation between coincidently observed vertical polarized Ka-band brightness temperature and the temperature of the land surface, referred to as $T_{\mathrm{Ka}}$. In this paper the Ka-band brightness temperature signal is degraded synthetically by adding a mean-zero, Gaussian random noise signal (uncorrelated in both time and space) to original Ka-band LST retrievals. Here, standard deviations of $0.5,1,2$ and $4 \mathrm{~K}$ are used for these synthetic random perturbations. These levels are chosen to represent realistic error levels of various LST products (Holmes et al., 2011), with the $4 \mathrm{~K}$ level being an extreme level of degradation over the Ka-band temperature product.

\subsubsection{MERRA scenarios}

The LST from the MERRA re-analysis data set, referred to as $T_{\text {MERRA }}$, represents a much shallower layer as the C- and $\mathrm{X}$ band radiation originates from a somewhat deeper layer $(\sim 1-$ $2 \mathrm{~cm}$ ). Because the temperature gradients may be substantial in the top centimetres of the soil, even such a small difference in vertical representation may result in systemic diurnal biases in temperature. As a result, the phase and amplitude of $T_{\text {MERRA }}$ is likely not optimally suited to represent the LST in soil moisture retrieval algorithms like LPRM. In order to better represent the temperature of the emitting layer of $\mathrm{C}$ and $\mathrm{X}$ - band microwave emission, and therefore make better use of the MERRA dataset as input to LRPM, we test different scenarios in which the vertical depth of the soil layer of MERRA predictions is increased.

The vertical distance between two measurement depths and the thermal properties of the medium determine the length of the time lag between soil temperature measurements at two different depths. Van Wijk and de Vries (1963) showed that a phase shift is accompanied by an exponential reduction in amplitude $(A)$ and an increase in phase shift $(d \phi)$ of the daily temperature cycle as the measurement depth is moved deeper into the soil Eqs. (6) and (7).

$$
\begin{aligned}
& A_{z 2}=A_{z 1} e\left(\frac{d z}{z_{\mathrm{d}}}\right) \\
& d \varphi=\frac{-d z}{z_{\mathrm{d}}}
\end{aligned}
$$

where $d z$ is the vertical distance $\left(z_{2}-z_{1}\right)$ and the damping depth $\left(z_{\mathrm{d}}\right)$ is an expression of the thermal properties of the medium. Holmes et al. (2011) demonstrated that by using only the measured phase shift between temperature records from two depths, a time series of temperature data can be synchronised to estimate the temperature at a second depth according to Eqs. (6) and (7). Specifically, they found that a $3 \mathrm{~h}$ phase shift applied to the original MERRA product could 


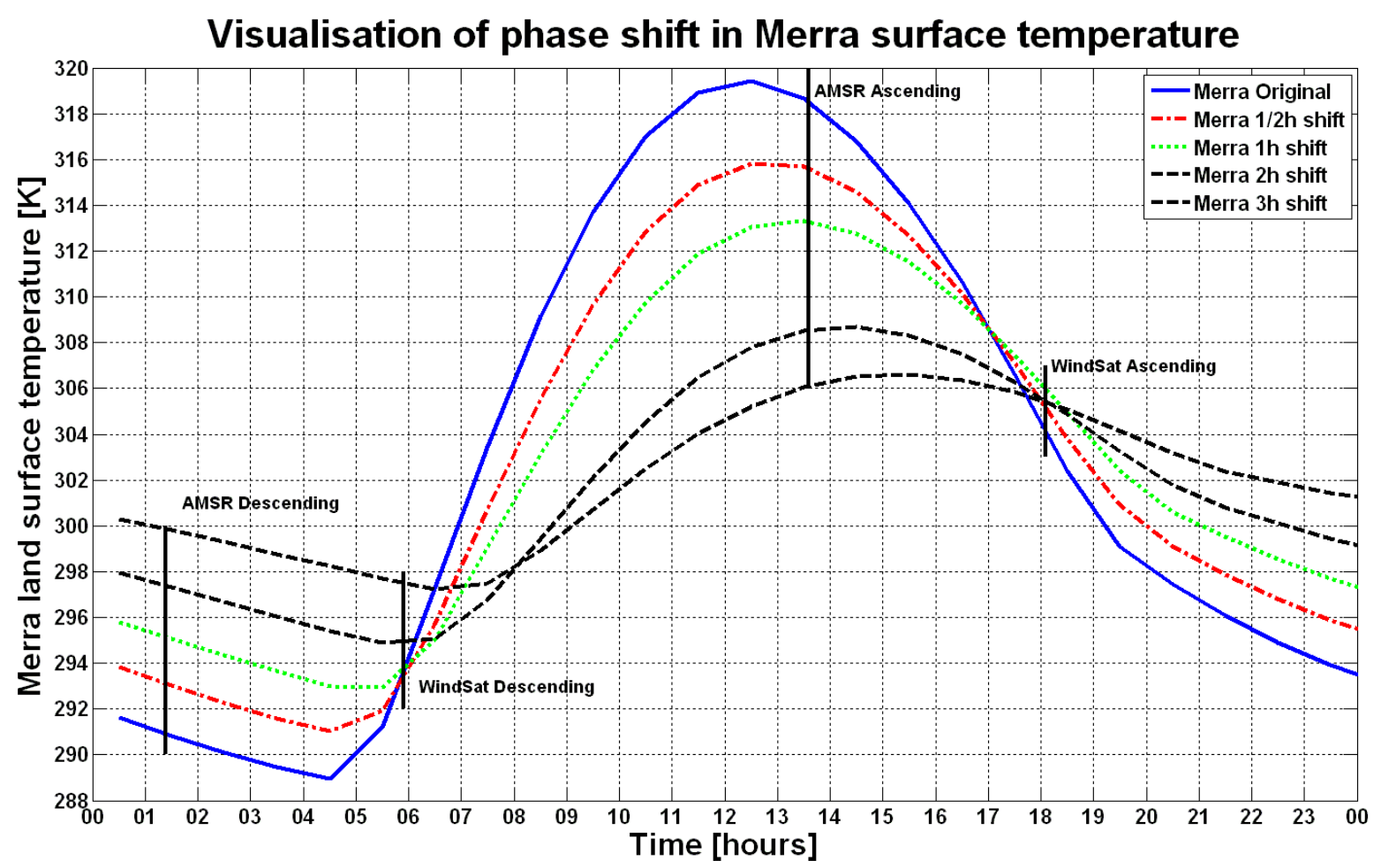

Fig. 6. Detailed diurnal land surface temperature time series from MERRA for 1 July 2009 in Oklahoma, United States of America. Different colours/line styles indicate different phase shifts which are related to different depths in the soil.

estimate the temperature at $5 \mathrm{~cm}$ below the surface with an RMSE of $1.8 \mathrm{~K}$ for a dense in situ network located in Oklahoma. For the present study a much smaller phase shift should be appropriate to estimate the temperature at $\sim 1-$ $2 \mathrm{~cm}$, but the exact value is difficult to estimate because it may depend on land cover and surface state. For this reason several different scenarios from the MERRA re-analysis LST dataset were evaluated for three different cases: (1) no phase lag (i.e. the original estimate), (2) a phase shift of $1 / 2 \mathrm{~h}$ and (3) a phase shift of $1 \mathrm{~h}$. For a single pixel in Oklahoma (USA), Fig. 6 demonstrates the impact (time-lag and amplitude reduction) of these phase shift on MERRA LST estimates. In addition to the evaluated MERRA scenarios (original, $1 / 2 \mathrm{~h}$ and $1 \mathrm{~h}$ ), a 2 and $3 \mathrm{~h}$ phase shift was included in Fig. 6 (for visualization purposes only), showing the damping in the amplitude and the associated timelag as a result of the introduced phase shift. This figure also shows that the soil temperature profile is more vertically homogeneous at the Coriolis/WindSat overpass time (06:00 a.m./p.m. local solar time) than at the Aqua/AMSRE retrieval time (01:30 a.m./p.m.).

\section{Results and discussion}

\subsection{Cross-verification}

Soil moisture retrievals from the night-time (descending) AMSR-E observations are used for cross-verification of the outputs of the two evaluation techniques introduced above (TC and $R_{\text {value }}$ ). Since the soil moisture data sets have been processed (scaling procedure: 3.1.2), TC-based RMSE and $R_{\text {value }}$ should contain essentially the same information (Entekhabi et al., 2010a) if both evaluation procedures are operating correctly. Figure 7 explores this issue in greater detail by showing a scatterplot between TC and the $R_{\text {value }}$ results over the entire range of LPRM-derived canopy optical depths $(\tau)$ (see Fig. 2). Over this range $(0<\tau<1.10)$ global RMSE acquired from the TC technique and global $R_{\text {value }}$ results are selected and averaged within a series of $\tau=0.01$ intervals, resulting in a set of 110 data pairs (Fig. 7). The coefficient of determination $\left(R^{2}\right)$ between the two evaluation techniques was high $\left(R^{2}=0.90\right)$. However, Fig. 7 does show deviations from the regression line in both the high and low extremes of the vegetation (class 1 and 6). The high mutual consistency between TC and $R_{\text {value }}$, which was shown in the other classes, breaks down at extreme vegetation levels due to a lack of variation in the $R_{\text {value }}$ metric, suggesting that

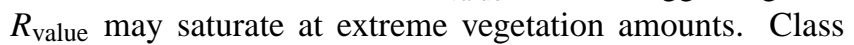
$1(\tau<0.10)$ mainly represents desert areas with only few 


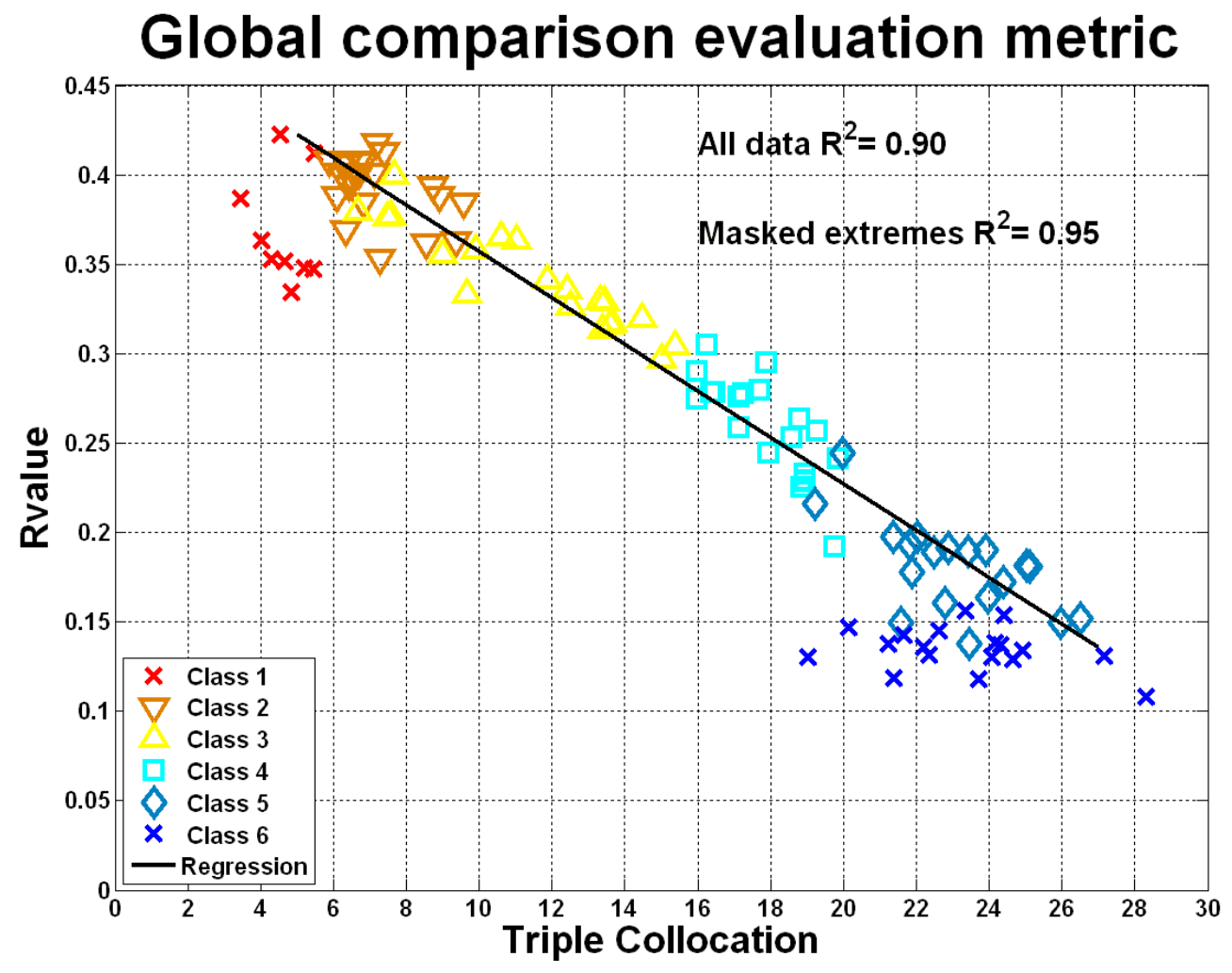

Fig. 7. Comparison of soil moisture anomaly skill according to the TC and the $R_{\text {value }}$ techniques for AMSR-E night-time (descending) retrievals. The vegetation classes refer to ranges of canopy optical depth defined in Table 1. Masked extremes refer to the vegetation classes 1 and 6 (Table 1 and Fig. 3).

precipitation events. For this reason the $R_{\text {value verification }}$ technique, which requires sampling across a large number of precipitation events, may lose sensitivity in very arid climate regions. On the other end of the scatterplot, class 6 (mainly rainforest areas), the deviation could be explained by the fact that the soil moisture signal becomes almost entirely masked due to the overlying canopy. When these two extreme vegetation regions (i.e. vegetation classes 1 and 6) are masked the coefficient of determination between the two evaluation techniques is very high $\left(R^{2}=0.95\right)$. This high level of consistency between the two techniques lends confidence to their interpretation as robust evaluation metrics for soil moisture retrievals.

\subsection{Ka-band scenarios}

As described in Sect. 3.2.1, $T_{\mathrm{ka}}$ retrievals were synthetically degraded using four different noise levels and then applied to generate a range of LPRM AMSR-E and WindSat-based soil moisture products. These products were then evaluated based on both the $R_{\text {value }}$ and TC verification techniques. Results within the 6 vegetation optical depth classes, as was shown in Fig. 3 (Table 1), were averaged resulting in Fig. 8. The left part of this figure shows the anomaly detection skill according to the $R_{\text {value }}$ technique, while the right part shows the skill according to the TC technique. Figure 8 shows that results of the $R_{\text {value }}$ evaluation technique are again roughly inversely related to those of the TC evaluation technique. For both satellites (AMSR-E and WindSat) in both day- (ascending) and night-time (descending) retrievals, increasing the magnitude of the noise levels leads to a reduction in $R_{\text {value }}$ for all vegetation density classes (Fig. 8, left). The figure also shows a steady decrease in $R_{\text {value }}$ with increasing vegetation density which is consistent with expectations about the impact of vegetation density on the attenuation of microwave emission from the soil surface by the overlying canopy. As previously discussed (Sect. 4.1), this trend is broken for AMSR-E retrievals within class 1 (i.e. mainly desert areas) land cover conditions. For both satellites, the lowest $R_{\text {value }}$ are found in class 6 where the LPRM does not typically report retrievals.

Figure 8 (right) shows comparable results for the TC method. In contrast with the $R_{\text {value }}$ method, where an increasing value indicates a better soil moisture product, an increasing root mean square error (RMSE) indicates that the remotely sensed soil moisture product is of lower quality. For both satellites in both day- (ascending) and night-time (descending) retrievals the TC method confirms the findings of the $R_{\text {value }}$ method. Increasing the artificial noise level on the 

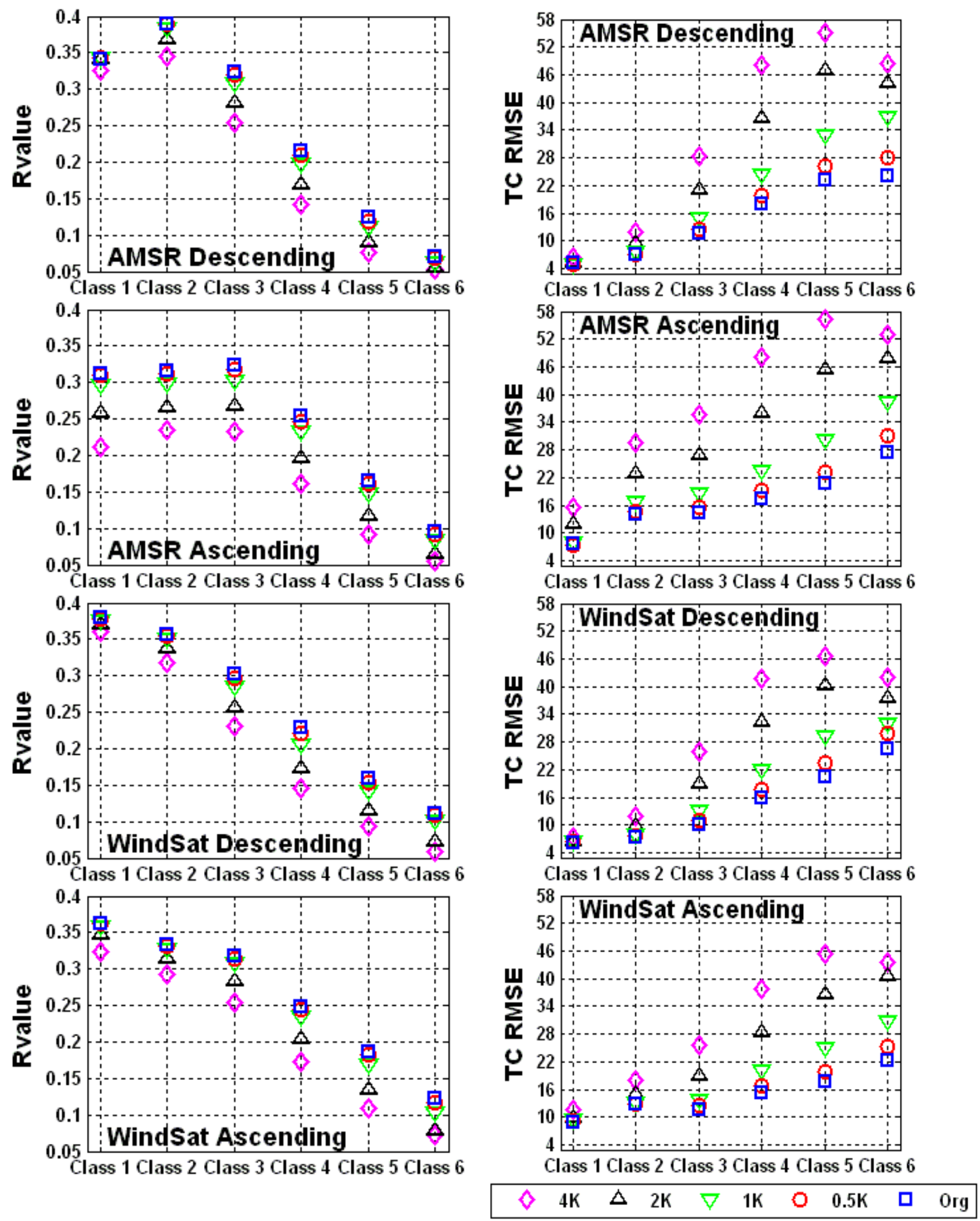

Fig. 8. Effect of degrading the $T_{\mathrm{Ka}}$ on the soil moisture anomaly detection skill according to the $R_{\mathrm{value}}$ (left) and the TC method (right) for the different overpass times of AMSR-E and WindSat. Each graph shows the average of the global results for six different vegetation classes (Table 1), and the different symbols indicate the level of artificial Gaussian noise applied to the $T_{\mathrm{Ka}}$ before inputting to the retrieval algorithm. 
Class 2
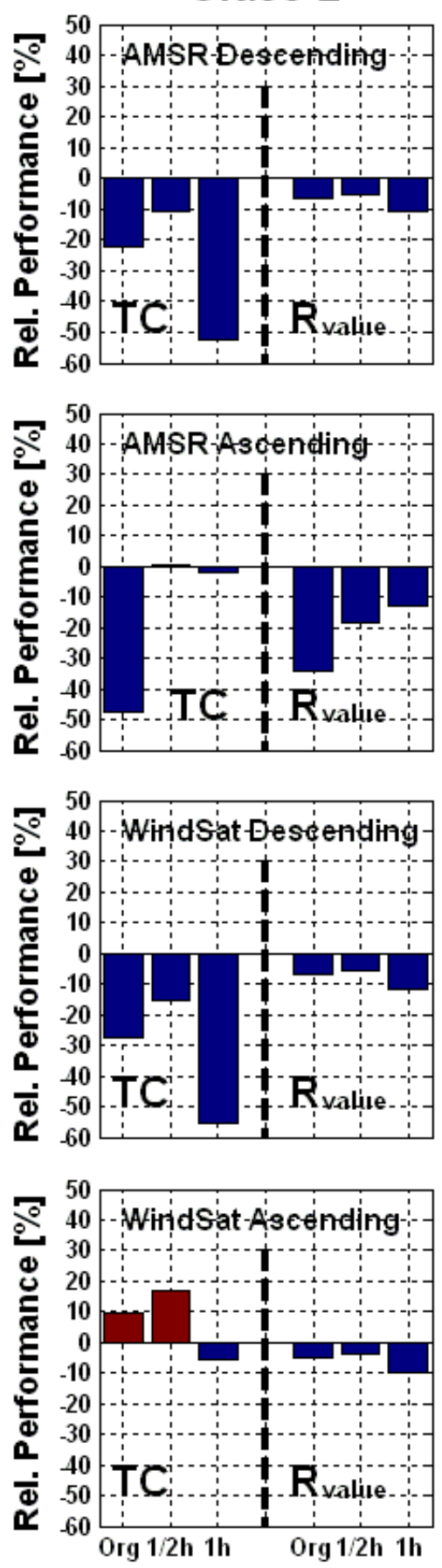

Class 3
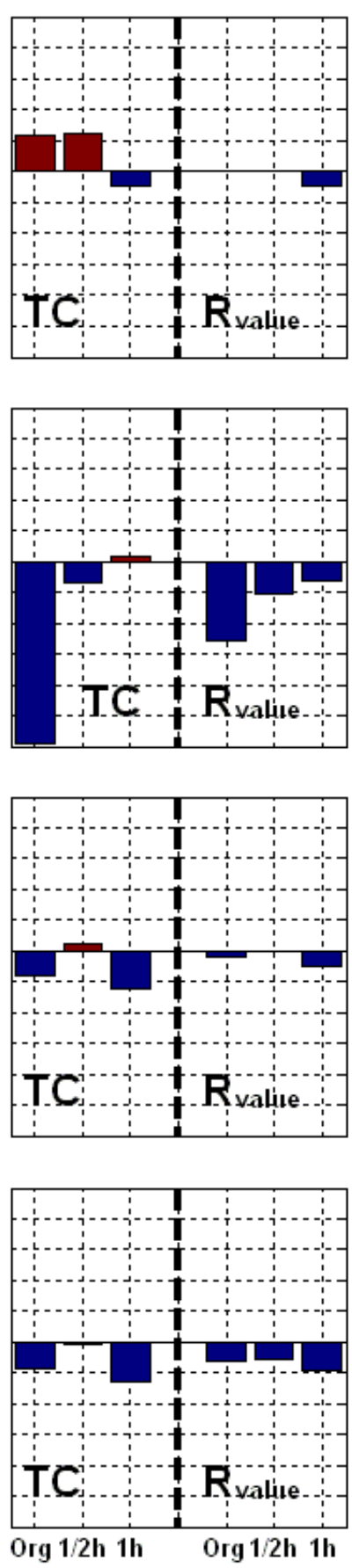

Class 4
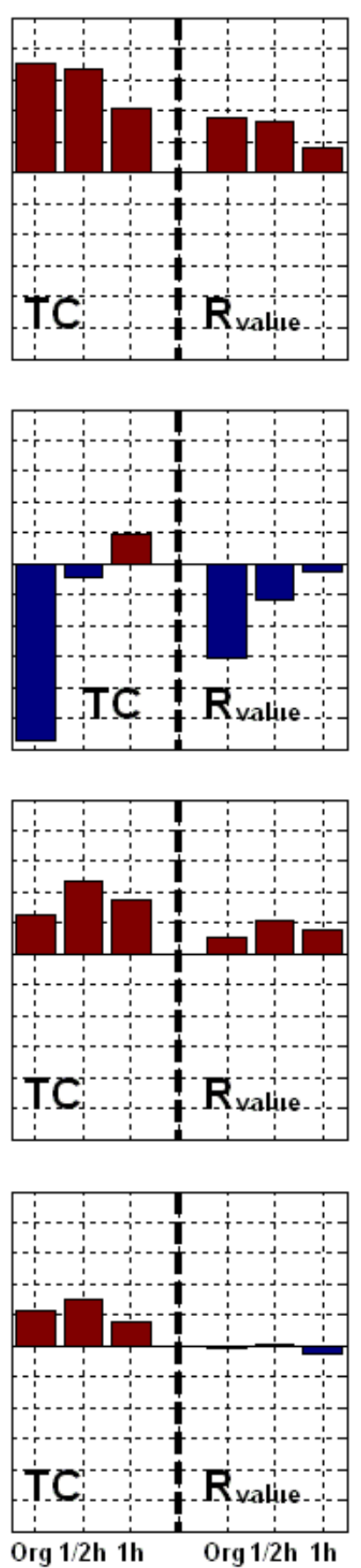

Class 5
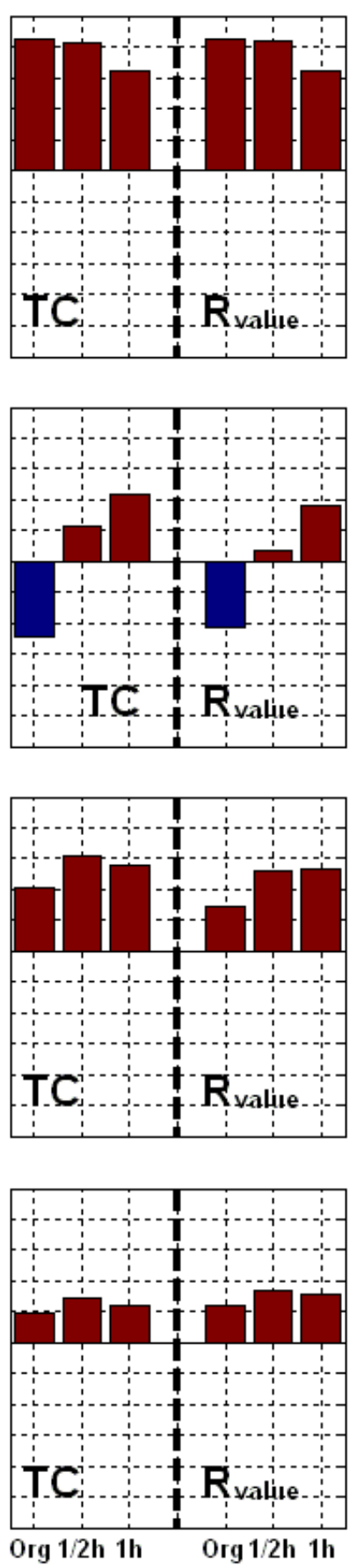

Fig. 9. The relative skill in anomaly detection according to the TC and $R_{\text {value }}$ techniques for three $T_{\text {MERRA }}$ scenarios representing different soil depths. The $\mathrm{x}$-axis represents the different MERRA scenarios (Original, $1 / 2 \mathrm{~h}$ - and $1 \mathrm{~h}$ phase shift), and the $\mathrm{y}$-axis captures the improvements (red) or degradation (blue) relative to the baseline case. Each row shows the results for a different observation time as based on AMSR-E (01:30 a.m./p.m.) and WindSat (06:00 a.m./p.m.). The results are further subdivided based on vegetation classes 2-5 (Table 1). 
$T_{\mathrm{ka}}$ inputs into LPRM leads to an increase in TC-estimated RMSE for subsequent LPRM soil moisture retrievals. Likewise, increasing vegetation density leads to a steady increase in TC-estimate RMSE for soil moisture retrievals. As was the case for $R_{\text {value }}$, the highest TC-estimated RMSE values are found for very densely-vegetated surfaces (i.e. class 6) which are typically masked in LPRM applications. This offers some confidence that TC can accurately identify areas of very poor retrieval accuracy. Finally, the similar response for both satellites with regards to variations in LST noise and vegetation density indicates that the lower spatial support of the WindSat sensor does not influence the results of the evaluation techniques.

Figure 8 also suggests that the LPRM has varying sensitivity to the surface temperature input under different vegetation conditions. Generally, the results of the evaluation techniques for the different noise scenarios cluster in the extreme classes (1 and 6) suggesting a lower sensitivity of the LPRM to LST in these areas. In the other classes $(2-5)$ the distribution for the different noise scenarios show a wider spread, indicating a higher sensitivity. Generally, this trend was confirmed by both verification techniques.

Another important observations from Fig. 8, is that daytime observations from both satellites become of higher quality when the vegetation density increases compared to the night-time observations over the same areas. Several studies (Loew and Schlenz, 2011; Brocca et al., 2011) indicated this already, but none of them explained this phenomenon. One possible explanation is that the vegetation water content during the day decreases due to transpiration induced by photosynthesis, making the vegetation more transparent to microwave emission, and consequently increasing the sensitivity to the underlying soil moisture signal. In general, for the majority of vegetation species the dry wood density is smaller than the density of water leading to a decrease in vegetation bulk densities when vegetation water content decreases. Also, higher canopy temperatures during the day could lead to decreased vegetation optical depth values, resulting in the same higher penetration through the overlying canopy. In any case, these findings show that the traditional view, which expects a higher quality of night-time observations since the environmental state is closer to equilibrium at these times (de Jeu et al., 2008) might be incomplete.

\subsection{MERRA scenarios}

The TC and $R_{\text {value }}$ evaluation techniques were also applied to soil moisture retrievals using the 3 different $T_{\text {MERRA }}$ scenarios (Table 3) and results within the 6 vegetation classes (Table 1; Fig. 3) were averaged. Figure 9 show these results for both evaluation techniques, where the relative degradation (negative values; blue areas) or improvement (positive values; red areas) compared to the original retrieval strategy (LPRM using $T_{\mathrm{Ka}}$ ) are plotted. Since the mutual consistency between both evaluation techniques was shown to break down at the high and low extremes of vegetation density (Sect. 4.1), only the results for vegetation classes 2 to 5 are presented here.

First, Fig. 9 is analyzed without differentiating results from the individual MERRA scenarios. Overall there is a trend between the relative performance of LPRM soil moisture retrievals using $T_{\mathrm{MERRA}}$ (versus $T_{\mathrm{Ka}}$ ) and the vegetation density. In the lightly-vegetated classes (2 and 3), the performance of the soil moisture retrievals degrades when $T_{\text {MERRA }}$ was used relative to $T_{\mathrm{Ka}}$ (majority is blue), the average degradation over all MERRA scenario's in these classes is $9.7 \%$. However, the use of MERRA-based soil moisture retrievals actually improves LPRM soil moisture retrieval accuracy for class 4 and 5 (majority is red), on average this improvement is $13.7 \%$. A general consistency between the TC- and the $R_{\text {value }}$ evaluation techniques is again apparent. There are some deviations between the performance of the two methods, but these are generally small (e.g. WindSat Ascending, class 2; AMSR-E Descending, class 3) or they are from observations taken under challenging conditions (AMSR-E Ascending; dense vegetation class 5). The relative impact of changing between $T_{\mathrm{Ka}}$ and $T_{\mathrm{MERRA}}$ tend to be larger for AMSR-E than for WindSat. This suggests that 01:30 a.m./p.m. (i.e. AMSR-E) observations are generally more sensitive to the transition from satellite observed LST to re-analysis LST than 06:00 a.m./p.m. (i.e. WindSat) observations.

Secondly, the impact of modifying the represented depth of $T_{\text {MERRA }}$ estimates, via Eqs. (6) and (7), is analyzed. Generalizing these results is not straightforward since Fig. 9 shows a large variety of responses to this modification between the different satellites and their individual paths. AMSR-E day-time (ascending) observations deviate significantly when compared to the other analyses and generally show improved results with increasing phase shift. A one hour phase shift shows the best results for AMSR-E day-time (ascending) observations, which could reflect an overestimation of the diurnal heating as shown previously in Holmes et al. (2011). Conversely, for AMSR-E night-time (descending) and WindSat (both paths) a $1 / 2 \mathrm{~h}$ phase shift in the $T_{\text {MERRA }}$ dataset is optimal under low- to sparsely vegetated conditions (classes 2 and 3).

\section{Conclusions and outlook}

The results of this study show the impact of LST error on the anomaly detection skill of surface soil moisture retrievals derived from the Land Parameter Retrieval Model (LPRM). LST is an input to the LPRM and is normally acquired from coincident Ka-band observations. In this study retrieved soil moisture from this default scenario is first compared to several scenarios where the Ka-band temperature input is synthetically degraded, and then to scenarios where LST is acquired from the MERRA re-analysis data. Two large-scale 
evaluation techniques, the $R_{\text {value }}$ metric and the triple collocation (TC) method, both show sensitivity to soil moisture retrieval skill when the quality of the LST signal is synthetically degraded. Moreover, a very high correlation $\left(R^{2}=\right.$ $0.95)$ between the two evaluation techniques was demonstrated when extreme vegetation conditions were masked. This consistency lends credibility to results obtained from both metrics.

It was also shown that both evaluated LST products manifest themselves differently in the LPRM under different vegetation conditions. This finding may be related to the nature of MERRA and Ka-band LST estimates and how differences between the two estimates manifest themselves and/or interact under certain vegetation conditions. Ka-band LST is directly related to the true radiometric temperature of the land surface and is observed simultaneously to the other satellite observations while MERRA LST estimates are based on the use of a coupled land-atmospheric model to temporally smooth between assimilated observations of surface and atmospheric states. As a result, MERRA LST estimates tend to be temporally smoother than instantaneous Ka-band LST retrievals. Since vegetation also tends to reduce the (high frequency) temporal variation of LST, such conditions may be better suited for the application of MERRA-based LST than lightly-vegetated conditions. Likewise, MERRA LST estimates are likely of higher quality for dense vegetation cases since LST is tightly coupled to air temperature and presumably easier to estimate within an atmospheric reanalysis system. These differences and their interaction result in favourable results for Ka-band LST estimates (relative to MERRA LST) for bare to sparse vegetation cases (classes 2-3), however this tendency is reversed for the moderate to dense vegetation cases (classes 4-5). Consequently, the global impact of transitioning into MERRA-based LST product is relatively modest.

Since the MERRA LST estimates do not have the same vertical representation of the soil layer as the Ka-band LST estimates we included two additional scenarios where a phase and amplitude adjustment of $1 / 2$ and $1 \mathrm{~h}$ represented slightly deeper temperature levels. The response to this phase shift on the accuracy of LPRM soil moisture retrievals obtained from MERRA LST varies considerably between each case. However, Fig. 9 suggests that under sparsely vegetated conditions (class $2-3$ ), introducing a $1 / 2 \mathrm{~h}$ phase shift generally outperforms the other MERRA scenarios.

The above results are based on the application of recent large-scale soil moisture evaluation techniques, and not on more commonly used comparisons with ground-based soil moisture observations. Arguably, these two techniques are less reliable than more direct validation against ground-based soil moisture observations; however, the fact that key conclusions are supported by both TC and $R_{\text {value }}$ evaluation techniques lends extra credence to their validity to evaluate soil moisture retrievals.
The results further suggest that AMSR (01:30 a.m./p.m.) observations are more sensitive to the transition from satellite observed LST to re-analysis LST than WindSat (06:00 a.m./p.m.) observations. This is an important finding, since the current (SMOS) and future (SMAP) satellite both have similar overpass times (06:00 a.m./p.m.) as the WindSat satellite. The transition from C-band WindSat and AMSR-E results to L-band SMAP and SMOS is widely expected to yield improved surface soil moisture retrievals. However, WindSat and AMSR-E retain the advantage of a Ka-band for LST retrievals while SMAP and SMOS are (or will be) forced to estimate LST from ancillary data (e.g. reanalysis or near real time data from weather prediction centres). Since, at least for some vegetation types, the use of this ancillary data appears associated with degradation in retrieval accuracy, a recommendation for future studies would be to include SMOS soil moisture retrievals to evaluate the magnitude of these LST degradations relative to the overall advantages associated with using lower frequency L-band radiometry to retrieve surface soil moisture. The work presented in this paper could be used as a framework for such evaluations.

Acknowledgements. This research was NASA-supported through Wade Crow's membership on the NASA SMAP mission science definition team.

Edited by: W. Wagner

\section{References}

Albergel, C., Calvet, J.-C., de Rosnay, P., Balsamo, G., Wagner, W., Hasenauer, S., Naeimi, V., Martin, E., Bazile, E., Bouyssel, F., and Mahfouf, J.-F.: Cross-evaluation of modelled and remotely sensed surface soil moisture with in situ data in southwestern France, Hydrol. Earth Syst. Sci., 14, 2177-2191, doi:10.5194/hess-14-2177-2010, 2010.

Brocca, L., Melone, F., Moramarco, T., Wagner, W., Naeimi, V., Bartalis, Z., and Hasenauer, S.: Improving runoff prediction through the assimilation of the ASCAT soil moisture product, Hydrol. Earth Syst. Sci., 14, 1881-1893, doi:10.5194/hess-141881-2010, 2010.

Brocca, L., Hasenauer, S., Lacava, T., Melone, F., Moramarco, T., Wagner, W., Dorigo, W., Matgen, P., Martinez-Fernandez, J., Llorens, P., Latron, J., Martin, C., and Bittelli, M.: Soil moisture estimation through ASCAT and AMSR-E sensors: An intercomparison and validation study across Europe, Remote Sens. Environ., in press, 2011.

Bisselink, B., van Meijgaard, E., Dolman, A., and de Jeu, R.: Initializing a regional climate model with satellitederived soil moisture, J. Geophys. Res., 116, D02121, doi:10.1029/2010JD014534, 2011.

Crow, W. and van den Berg, M.: An improved approach for estimating observation and model error parameters for soil moisture data assimilation. Water Resour. Res., 46, W12519, doi:10.1029/2010WR009402, 2010. 
Crow, W. and Zhan, X.: Continental-Scale Evaluation of Remotely Sensed Soil Moisture Products, IEEE T. Geosci. Remote Sens., 4, 451-455, 2007.

Crow, W., Miralles, D., and Cosh, M.: A Quasi-Global Evaluation System for Satellite-Based Surface Soil Moisture Retrievals, IEEE T. Geosci. Remote Sens., 48, 2516-2527, 2010 a.

Dorigo, W. A., Scipal, K., Parinussa, R. M., Liu, Y. Y., Wagner, W., de Jeu, R. A. M., and Naeimi, V.: Error characterisation of global active and passive microwave soil moisture datasets, Hydrol. Earth Syst. Sci., 14, 2605-2616, doi:10.5194/hess-142605-2010, 2010.

Draper, C., Walker, J., Steinle, P., de Jeu, R., and Holmes, T.: An Evaluation of AMSR-E Derived Soil Moisture over Australia, Remote Sens. Environ., 113, 703-710, 2009.

Entekhabi, D., Reichle, R., Koster, R., and Crow, W.: Performance Metrics for Soil Moisture Retrievals and Application Requirements, J. Hydrometeorol., 11, 832-840, 2010a.

Entekhabi, D., Njoku E., O’Neill, P., Kellogg, K., Crow, W., Edelstein, W., Entin, J., Goodman, S., Jackson, T., Johnson, J., Kimball, J., Piepmeier, J., Koster, R., McDonald, K., Moghaddam, M., Moran, S., Reichle, R., Shi, J., Spencer, M., Thurman, S., Tsang, L., and van Zyl, J.: The Soil Moisture Active and Passive (SMAP) Mission, Proc. IEEE, 98, 704-716, 2010b.

Figa-Saldana, J., Wilson, J., Attema, E., Gelsthorpe, R., Drinkwater, M., and Stofellen, A.: The advanced scatterometer (ASCAT) on the meteorological operational (MetOp) platform: A follow on for European wind scatterometers, J. Remote Sens., 28, 404412, 2002.

Gaiser, P., St. Germain, K., Twarog, E., Poe, G., Purdy, W., Richardson, D., Grossman, W., Jones, W., Spencer, D., Golba, G., Cleveland, J., Choy, L., Bevilacqua, R., and Chang, P.: The WindSat Spaceborne Polarimetric Microwave Radiometer: Sensor Description and Early Orbit Performance, IEEE T. Geosci. Remote Sens., 42, 2347-2360, 2004.

Holmes, T., de Jeu, R., Owe, M., and Dolman, A.: Land surface temperature from $\mathrm{Ka}$ band passive microwave observations, J. Geophys. Res. Atmos., 114, D04113, doi:10.1029/2008JD010257, 2009.

Holmes, T., Jackson, J., Reichle, R., and Basara, J.: An Assessment of Surface Soil Temperature Products from Numerical Weather Prediction Models Using Ground-based Measurements, accepted, 2011.

Huffman, G., Adler, R., Bolvin, D., Gu, G., Nelkin, E., Bowman, K., Hong, Y., Stocker, E., and Wolff, D.: The TRMM Multisatellite Precipitation Analysis (TMPA): Quasi-Global, Multiyear, Combined-Sensor Precipitation Estimates at Fine Scales, J. Hydrometeorol., 8, 38-55, 2007.

Jackson, T. and Schmugge, T.: Passive microwave remote sensing system for soil moisture: Some supporting research, IEEE T. Geosci. Remote Sens., 27, 225-235, 1989.

Jackson, T., Hurkmans, R., Hsu A., and Cosh, M.: Soil moisture algorithm validation using data from the Advanced Microwave Scanning Radiometer (AMSR-E) in Mongolia, Riv. Ital. Telerilevam., 30, 37-50, 2004.

Jackson, T., Cosh, M., Bindlish, R., Starks, P., Bosch, D., Seyfried, M., Goodrich, D., Moran, M., and Du, J.: Validation of Advanced Microwave Scanning Radiometer Soil Moisture, IEEE T. Geosci. Remote Sens., 48, 4256-4272, 2010.

de Jeu, R. and Owe, M.: Further validation of a new methodology for surface moisture and vegetation optical depth retrieval, Int. J. Remote Sens., 24, 4559-4578, 2003.

de Jeu, R., Wagner, W., Holmes, T., Dolman, A., van de Giesen, N., and Friesen, J.: Global Soil Moisture Patterns Observed by Space Borne Microwave Radiometers and Scatterometers, Surv. Geophys., 29, 399-420, 2008.

Kerr, Y., Waldteufel, P., Wigneron, J-P., Delwart, S., Cabot, F., Boutin, J., Escorihuela, M-J., Font, J., Reul, N., Gruhier, C., Enache Juglea, S., Drinkwater, M., Hahne, A., Martin-Neira, M., and Mecklenburg, S.: The SMOS Mission: New Tool for Monitoring Key Elements of the Global Water Cycle, Proc. IEEE, 98, 667-687, 2010.

Li, L., Njoku, E., Im, E., Chang P., and Germaine K.: A preliminary survey of radio-frequency interference over the US in Aqua AMSR-E data, IEEE T. Geosci. Remote Sens., 42, 380-390, 2004.

Li, L., Gaiser, W., Gao, B., Bevilacque, R., Jackson, T., Njoku, E., Rudiger, C., Calvet, J., and Bindlish, R.: WindSat Global Soil Moisture Retrieval and Validation, IEEE T. Geosci. Remote Sens., 48, 2224-2241, 2010.

Loew, A. and Schlenz, F.: A dynamic approach for evaluating coarse scale satellite soil moisture products, Hydrol. Earth Syst Sci., 15, 75-90, doi:10.5194/hess-15-75-2011, 2011.

Loew, A., Holmes, T., and de Jeu, R.: The European heat wave 2003: Early indicators from multisensoral microwave remote sensing?, J. Geophys. Res., 114, D05103, doi:10.1029/2008JD010533, 2009.

Meesters, A., de Jeu, R., and Owe, M.: Analytical derivation of the vegetation optical depth from the microwave polarization difference index, IEEE T. Geosci. Remote Sens., 2, 121-123, 2005.

Miralles, D. G., Crow, W., and Cosh, M.: Estimating Spatial Sampling Errors in Coarse-Scale Soil Moisture Estimates Derived from Point-Scale Observations, J. Hydrometeorol, 11, 14231429, 2010.

Miralles, D. G., Holmes, T. R. H., De Jeu, R. A. M., Gash, J. H., Meesters, A. G. C. A., and Dolman, A. J.: Global landsurface evaporation estimated from satellite-based observations, Hydrol. Earth Syst. Sci., 15, 453-469, doi:10.5194/hess-15-4532011, 2011.

Naeimi, V., Scipal, K., Bartalis, Z., Hasenauer, S., and Wagner, W.: An Improved Soil Moisture Retrieval Algorithm for ERS and METOP Scatterometer Observations, IEEE T. Geosci. Remote Sens., 47, 1999-2013, 2009.

NSIDC: National Snow and Ice Data Centre, Data products and services, Boulder Colo, 2006

Owe, M., de Jeu, R., and Holmes, T.: Multisensor historical climatology of satellite-derived global land surface moisture, J. Geophys. Res. Earth Surf., 113, F01002, doi:10.1029/2007JF000769, 2008.

Parinussa, R., Holmes, T., and de Jeu, R.: Soil moisture retrievals from the WindSat spaceborne polarimetric microwave radiometer, IEEE T. Geosci. Remote Sens., accepted, 2011.

Reichle, R. and Koster, R.: Bias reduction in short records of satellite soil moisture, Geophys. Res. Lett., 31, L19501, doi:10.1029/2004GL020938, 2004.

Rienecker, M., Suarez, M., Gelaro, R., Todling, R., Bacmeister, J., Liu, E., Bosilovich, M.,Schubert, S., Takacs, L., Kim, G., Bloom, S., Chen, J., Collins, D., Conaty, A., da Silva, A., Gu, W., Joiner, J., Koster, R., Lucchesi, R., Molod, A., Owes, T., 
Pawson, S., Pegion, P., Redder, C., Reichle, R., Robertson, F., Ruddick, A., Sienkiewicz, M. and, Woollen, J.: MERRA NASA's Modern-Era Retrospective Analysis for Research and Applications, available at:http://gmao.gsfc.nasa.gov/pubs/docs/ Rienecker443.pdf, last access: July 2011, J. Climate, submitted, 2011.

Schmugge, T.: Remote sensing of soil moisture: Recent advances, IEEE T. Geosci. Remote Sens., 21, 145-146, 1983.

Scipal, K., Holmes, T., de Jeu, R., Naeimi, V., and Wagner, W.: A possible solution for the problem of estimating the error structure of global soil moisture data sets, Geophys. Res. Lett., 35, L24403, doi:10.1029/2008GL035599, 2008.
Stoffelen, A.: Towards the true near surface wind speed: Error modelling and calibration using triple collocation, J. Geophys. Res., 103, 5767-5780, 1998.

Wagner, W., Lemoine, G., and Rott, H.: A method for estimating soil moisture from ERS scatterometer and soil data, Remote Sens. Eviron., 70, 191-207, 1999.

Wagner, W., Naeimi, V., Scipal, K., de Jeu, R., and MartinezFernandez J.: Soil moisture from operational meteorological satellites, Hydrogeol. J., 15, 121-131, 2007.

van Wijk, W. and de Vries, D.: Periodic temperature variations in a homogeneous soil, Phys. Plant Environ., North-Holland Publ. Co., Amsterdam, 102-143, 1963. 